International Journal of Medical Sciences

ISSN 1449-1907 www.medsci.org 2005 2(3):93-99

Review

(C)2005 Ivyspring International Publisher. All rights reserved

\title{
Primary prevention of Down's syndrome
}

\section{Howard S Cuckle}

Reproductive Epidemiology, University of Leeds, UK

Corresponding address: Howard Cuckle, Reproductive Epidemiology, Leeds Screening Centre, Gemini Park, Sheepscar Way, Leeds LS7 3JB, UK. Tel: +44 1132849233 fax: +44 1132621675 e-mail: h.s.cuckle@leeds.ac.uk

Received: 2005.05.01; Accepted: 2005.05.25; Published: 2005.07.01

Background: Antenatal screening has the capacity to detect more than $90 \%$ of Down's syndrome pregnancies leading to therapeutic abortion. Successes in recent years with such so-called 'secondary' prevention have not been matched with progress in primary prevention. Despite considerable research over many decades the principle cause of the disorder is unknown.

Methods: This paper considers three potential primary prevention strategies, (1) avoiding reproduction at advanced maternal age, (2) pre-implantation genetic diagnosis for couples who are at high risk of Down's syndrome, and (3) folic acid supplementation. The principle aetiological hypotheses are also reviewed.

Interpretation: A strategy of completing the family before a maternal age of 30 could more than halve the birth prevalence of this disorder. Women with a high a priori risk should have access to pre-implantation genetic diagnosis, which can lead to a reasonably high pregnancy rate with an extremely low risk of a Down's syndrome. The evidence suggesting an aetiological role for defective folate and methyl metabolism is not sufficient to justify an active preventative strategy of folic acid supplementation without performing a large clinical trial. Current supplementation policies designed to prevent neural tube defects may incidentally prevent Down's syndrome, provided a sufficiently high dose of folic acid is used. Further progress in primary prevention is hampered by limited aetiological knowledge and there is an urgent need to refocus research in that direction.

K ey words: Primary prevention, maternal age, pre-implantation diagnosis, folic acid, aetiology

\section{Introduction}

Aneuploidy is a common event in pregnancy although most affected embryos abort spontaneously early in the first trimester. Those that survive into the second trimester also experience high late intrauterine mortality and increased risk of infant death. Viability and clinical outcome vary according to the genotype and this paper will concentrate on Down's syndrome (DS), the most common form of aneuploidy which is sufficiently viable to survive to term in relatively large numbers.

In the absence of prenatal diagnosis and therapeutic abortion, the prevalence of DS in developed countries is 12 per 1,000 births making it the most frequent identifiable cause of severe learning difficulty. In $95 \%$ of cases there is non-disjunction of chromosome 21 , in $4 \%$ a translocation and $1 \%$ are mosaic [1].

Advanced maternal age is by far the strongest epidemiological variables with birth prevalence increasing from 0.6 to 4.1 per 1,000 between age 15 and 45 [2]. There is familial aggregation: having had a previous DS pregnancy confers a risk 4.2 per 1,000 higher risk than the age-specific prevalence [3]. Other risk factors are considerably weaker [4].

DNA analysis in the parents of children with nondisjunction trisomy 21 shows that the extra chromosome is maternal in origin for about $90 \%$ and that certain types of cross-over during maternal meiosis confer a substantial susceptibility [5]. The parents also have an altered distribution of polymorphisms in the genes for apolipoprotein E [6], presenilin-1a [7], 5,10-methylenetetrahydrofolate reductase (MTHFR) and methionine synthase reductase (MTRR) [8-13]. The latter polymorphisms together with biochemical and epidemiological evidence suggest an association with impaired folate and homocystine metabolism [14].

In recent decades considerable attention has been given to the so-called 'secondary' prevention of DS through antenatal screening followed by invasive prenatal diagnosis and termination of affected pregnancies. In the past women were selected for prenatal diagnosis on the basis of high risk - largely advanced maternal age or family history. However, this had little impact on birth prevalence since most cases occur without any specific indication. Moreover, the advanced age group include a disproportionate number who would not accept termination for religious reasons and many who would not accept the hazards of invasive prenatal diagnosis after an extended period of infertility. Today the situation is very different. Antenatal screening using multiple biochemical and ultrasound markers is routine in developed countries. The best techniques are now capable of detecting more than $90 \%$ of affected pregnancies [15] and this approach appears to be generally acceptable to pregnant women [16]. These successes with so-called 'secondary' prevention have not been matched with progress in primary prevention. Despite considerable research over many decades the principle cause of DS is unclear. Nevertheless some preventative strategies might be considered: avoiding late reproduction, pre-implantation genetic diagnosis (PGD) and folic acid supplementation. To make further progress there is an urgent need to refocus aetiological research so as to build on recent findings.

\section{Avoiding late reproduction}

A simple preventative strategy that anyone can undertake is to complete their family at a relatively young 
age. The risk of an affected pregnancy will remain but could be substantially reduced.

\subsection{Maternal age-specific risk}

The best available estimate of the risk of an affected term pregnancy is obtained from combining data from published series of birth prevalence for individual years of age which were carried out before prenatal diagnosis became common. Four such meta-analyses have been published based on eleven different maternal age specific birth prevalence series. The studies differed in the number of series included, the method of pooling series, the type of regression equation and the extent to which the maternal age range was restricted. As a result there are 19 published regression curves.

The most widely cited curve was based on all eight series published at that time with a total of 4-5,000 DS and more than 5 million unaffected births [2]. For each year of age data were pooled by taking the average birth prevalence rate across the series weighted by the number of births. Another curve used the same series but birth prevalence numerators and denominators were pooled; also a separate curve was derived pooling just the two series which the authors regarded to be most complete [17]. A third study extended these two series by adding more recent data, and pooled them with two newer series [18]. The last study included nine series, six of those used in [2], the four in [18] and a further new series [19]. Pooling made use of a weighting factor which estimates the proportional under-ascertainment in each series, and is derived simultaneously with the curve parameters.

There is little practical difference between the 19 curves over the 15-44 year age range but emerges later. By age 50 the risks range from 1 in 5 to 1 in 18 . Recently another curve has been published based on 11,000 cases from the National Down Syndrome Cytogenetic Register for England and Wales [20]. This curve differs significantly from the curve in [2] for older women: higher at age 36-41 and considerably lower after 45. However, unlike the other series, $45 \%$ of the cases were diagnosed prenatally and $82 \%$ of these ended in termination of pregnancy, potentially introducing a strong bias [21]. Birth prevalence was estimated by assuming an intrauterine survival rate following prenatal diagnosis derived from studies of older women [22]. This rate may not be applicable to women having prenatal diagnosis because of antenatal screening since they are younger, and extreme levels of the various screening markers are associated with non-viability.

\subsection{Impact of the strategy}

Knowing their increased DS risk an individual couple may decide to avoid pregnancy at an advanced age. This raises the possibility of a public health strategy based on routinely informing couples of their age-specific in a family planning context. It is not possible to judge how effectiveness this might be in practice but a theoretical maximum can be estimated for the overall impact on DS birth prevalence if all families are completed before different ages.

It is possible to estimate the DS birth prevalence of a specific country, in the absence of prenatal diagnosis, by the average age-specific risk of an affected term pregnancy weighted by the proportion of maternities at each completed year of age. Applying one of the above risk curves [2] to maternal age distribution for England and Wales in 2002 [23] yields prevalence of 1.89 per 1,000 births. If all families had been completed by age 30 and assuming that the age distribution was unaltered before that age the prevalence would only have been 0.80 per 1,000 , a $58 \%$ reduction. Completion by age 25 would reduce prevalence to 0.68 per 1000 or $64 \%$.

Whilst this is purely theoretical it should be noted that the maternal age distribution is not uniform over time. In England and Wales there has been a steady increase in the average maternal age in recent years. For example, in 1988 it was 26.7 years compared with 2002 when it was 28.8 years [24]. Consequently, the estimated DS birth prevalence in 1988 was 1.31 per 1,000, 30\% lower than in 2002.

\subsection{Paternal age-specific risk}

Maternal and paternal ages are highly correlated with relatively little variability in the age difference between the two parents. But if the male partner is substantially older than the mother the couple might consider completing their family while he is relatively young. However, there is little evidence for a large paternal age risk independent of the maternal age risk.

Given the correlation between ages an extremely large number of affected couples would have to be investigated in order to discern any independent paternal age effect. Consequently, some small studies have reported an effect [25-26], but many others found none.

The most compelling evidence for an effect comes from a study of French donor insemination centres, where there is a large age difference between donors and recipients [27]. A statistically significant effect of donor age was reported, but it was much smaller than the maternal age effect.

\section{Pre-implantation genetic diagnosis}

Assisted reproduction technologies developed to combat infertility are increasingly being used in couples at high risk of certain genetic inherited disorders. These couples can now be reasonably assured of a normal pregnancy by using a donor egg or sperm depending on which partner carries the risk. Moreover, the technique of PGD can be applied in order to achieve a normal pregnancy with the couples own gametes.

Initially the principle indication for PGD was an inherited single gene or X-liked disorder or for the small number of couples carrying a balance translocation. Now it is carried out for the more common situation where the couple are at high a priori risk because of a having had a previous child with standard trisomy or in some services were they are simply at advanced reproductive age.

The selection of normal embryos following PGD performed on blastomeres is not perfect and there is a residual risk of aneuploidy. An alternative PGD method based on fluorescence in-situ hybridisation (FISH) analysis of the first and second polar bodies has been developed to overcome this.

\subsection{DS recurrence risk}

When there is a parental structural chromosome rearrangement the recurrence risk can be quite high, depending on the specific genotype. For the most common genotype, a Robertsonian balanced translocation, if the mother is the carrier the recurrence risk is great enough to dwarf the age-specific risk at most ages, whilst in male carriers the risk is not high. For example, among 185 amniocenteses in carrier women $15 \%$ of fetuses had a 
translocation, whilst all 70 amniotic fluid samples had a normal karyotype when the man was a carrier [28].

Translocation carriers are usually identified as a result of karyotyping affected infants or in prenatal diagnosis. The finding of a structural rearrangement will lead to the parents and other close relatives being karyotyped. Another common situation is for a parental translocation to be found when couples with recurrent early miscarriages are karyotyped.

If a woman has had a previous pregnancy with Down's syndrome and the additional chromosome 21 was non-inherited there is still an increased risk of recurrence. The increase has been estimated at three points in pregnancy. In an unpublished study of more than 2,500 women who had first trimester invasive prenatal diagnosis because of a previous affected pregnancy, the Down's syndrome incidence was $0.75 \%$ higher than that expected from the maternal-age distribution (Kypros Nicolaides, personal communication). Similarly, a metaanalysis of four second trimester amniocentesis series totalling 4,953 pregnancies found an excess of $0.54 \%$ [3]. A meta-analysis of 433 livebirths had 5 recurrences, an excess risk of $0.52 \%$ [29]. The weighted average of these rates, allowing for fetal losses is $0.77 \%$ in the first trimester, $0.54 \%$ in the second and $0.42 \%$ at term. Examination of the data suggests that the excess is similar at different ages so the excess can be added to the agespecific risk expressed as a probability. The recurrence risk is relatively large for young women but by the age of about 40 it is not materially different from the risk in women without a family history.

Among women with non-inherited DS many are likely to have recurrence due to chance alone and a subset with a genetic cause. Mosaicism may be involved but is rarely seen in peripheral blood [30] even using molecular techniques [31]. Another possibility is inheritance of a cytoplasmic risk factor which is supported by data from families with either two DS cases or one DS and another aneuploidy in which there were different reproductive partners in the parental or grand-parental generation. There are 14 case reports of this nature in the literature and in all but one, from a highly inbred population, recurrence was on the maternal side [3].

\subsection{Experience with the technique}

Studies of pre-implantation embryos show that most have an aneuploid, mosaic or chaotic karyotype. And the frequency of euploidy is particularly uncommon when the parents have a balanced translocation, previous aneuploidy or advanced age. Nevertheless PGD can help to achieve a normal pregnancy in such couples who are at high a priori risk.

In a series of 49 couples with a balanced translocation treated in one centre, 1,408 oocytes were obtained and 938 were fertilised, of which one-fifth were normal or had a balanced translocation [32]. Following 64 treatment cycles some 20 pregnancies were established and 14 of the couples had a normal delivery. Among 48 women who had a previous pregnancy with noninherited aneuploidy there were 118 normal embryos among 378 examined [33]. In 41 treatment cycles 21 pregnancies were established. In one centre carrying out PGD for advanced reproductive age, using the polar body method 8,382 oocytes were obtained in 1,297 cycles from patients of advanced maternal age [34]. FISH was informative in $80 \%$ and nearly half were found to be euploid. Embryo transfer in 1,100 treatment cycles resulted in 241 clinical pregnancies and 176 normal deliveries.

\section{Folic acid supplementation}

There is a growing body of evidence suggesting that DS might be linked to abnormal folate and methyl metabolism. This can lead to DNA hypo-methylation, instability, abnormal segregation and aneuploidy [35-36]. Whilst the aetiological implications of the available data are uncertain, a case can now be made for performing a clinical trial to assess the possibility of primary prevention of DS by dietary supplementation. Meanwhile the strategy of folic acid supplementation designed to prevent fetal neural tube defects (NTDs) might incidentally reduce the DS risk provided a high enough dose is used.

\subsection{Evidence of a link}

A study of 41 mothers of DS infants found a statistically significant increase in plasma homocystine (Hcy) compared to controls [8]. Hcy is a sensitive marker of folate status that is inversely correlated with levels of folate in plasma, and both folate and methyl folate in red blood cells [37-38]. The study also found reduced methionine in cases and an increased ratio of plasma Hcy to methionine and increased sensitivity to methotrexate cytotoxicity - an indicator of functional folate metabolism.

There have been six studies of MTHFR polymorphisms and two studies of MTRR [8-13]. Some have reported increased frequency of the MTHFR 677C $\rightarrow$ T and MTRR 66A $\rightarrow$ G mutant alleles, overall or in subgroups, but the results are not consistent. Both MTHFR and MTRR mutations could be critical for DNA methylation. MTHFR catalyses the conversion of 5,10methylene-tetrahydrofolate (THF) to 5-methyl-THF, the methyl donor in the remethylation of homocysteine to methionine by methionine synthase, which in turn is maintained in its active form by MTRR.

The concept of a link with abnormal folate metabolism was given a boost by a recent study of 493 families who were at high NTD risk, 445 with a history of NTD and 48 with isolated hydrocephalus, there were 11 DS cases among 1,492 at risk pregnancies, compared with 1.87 expected on the basis of maternal age, a highly statistically significant excess [14]. In the same study a second series of 516 families at high risk of DS there were 7 NTD pregnancies among 1,847 at risk, compared with 1.37 expected.

But a network of congenital malformation registries in Latin America have failed to confirm these results [39]. When affected pregnancies are registered an interviewer takes a clinical history from the mother, including about previous affected pregnancies. The study identified five cases of Down's syndrome occurring among 5404 pregnancies previous to NTD or hydrocephalus, and 12 cases of NTD or hydrocephalus occurred among 8066 pregnancies previous to DS. Neither of these figures was excessive as the expected values based on prevalence within the network was 5.1 and 17.2 respectively. One possible explanation is the underreporting of familial cases. Registries are not well suited to this kind of investigation as they concentrate on individual cases rather than families and are generally poor at record linkage. It is also possible that the effect observed in Israel and Ukraine is not present in Latin America where the genetic basis of NTDs may differ. 


\subsection{Supplementation}

Dietary intervention studies show that genomic instability is minimised when the plasma folate level exceeds about $34 \mathrm{nmol} / 1$ and the Hcy level is less than 7.5 $\mu \mathrm{mol} / 1$ [35]. These levels can only be achieved when folic acid intake is above $5 \mathrm{mg}$ per day. Currently, the recommended daily dose for the prevention of NTDs in women with no previous affected pregnancies is $0.4 \mathrm{mg}$ but it has now been estimated that a much higher intake would be required to have a substantial benefit and the authors recommend $5 \mathrm{mg}$ [40]. The higher dose would increase serum folate levels 5-20 fold, depending on the background level. A meta-analysis of cardiac prevention trials found an average Hcy reduction of $25 \%$ for an intake of $2.2 \mathrm{mg}$ per day on average [41]. In another publication, five women with folate deficiencies who were given 10mg per day for two months there was, on average, a 53\% reduction in plasma Hcy [37].

Reductions in NTD prevalence over time and within non-randomised supplementation trials cannot be attributed to folic acid alone [40]. Another possibility is a defect in the metabolism or transport of vitamin $B_{12}$ (cobalamin) an essential cofactor in the folate-homocystine cycle. Low maternal levels are associated with increased NTD risk, independent of folate status [42] and the relative risk of NTD conferred by the MTRR G/G genotype is greater in mothers with levels in the lowest quartile [43]. Vitamin $B_{12}$ deficiency is also associated with genomic instability and when plasma levels fall below 300pmol/1 [35]. Adjuvant supplementation with cobalamin enhances the reduction of Hcy compared to folic acid alone [35,41].

An association has been found between spontaneous abortions and a polymorphism, Pro259Arg, in the gene for transcobalimin, a protein that binds cobalamin and transports it to peripheral tissue [44]. This may be regarded as further evidence of an NTD-DS link since a large proportion of abortuses have these defects. Low maternal blood folate levels are also associated with miscarriage [45].

A large trial of folic acid and possibly cobalamin supplementation would be needed before DS prevention can be established and a public health policy on the matter is justified. Meanwhile, the existing programs designed to prevent NTDs might incidentally prevent DS, although the higher $5 \mathrm{mg}$ dose would probably be needed.

\section{Aetiological research}

The risk factors highlighted by epidemiological study, particularly the maternal age effect, have given rise to a number of aetiological hypotheses. More focused research is urgently needed to test them in greater depth than in the past and in particular some recent aetiological clues should be built on.

\subsection{Production line hypothesis}

Oocytes formed in late fetal life have fewer chiasmata and more univalents, rendering them susceptible to non-disjunction. The production line hypothesis proposes that the order in which oocytes ovulate within a woman's reproductive life is determined by the order in which they were produced in utero [46]. It has been tested in animal models using various experimental methods with no clear and consistent supportive evidence [47-50].

\subsection{Ageing oocyte hypotheses}

The cause of DS has been sought in disturbances during stages of oogenesis, including the period of meiotic arrest of the oocyte [51]. This has generated several hypotheses.

One possibility is that the frequency of persistent nucleoli in MI prophase is increased in older women due to the long dictyate stage. This would lead to errors in meiotic segregation of acrocentric chromosomes where nucleolar fusion holds together the short arms [52]. However, this hypothesis and its variants could not explain trisomy among non-acrocentric chromosomes [53].

Over the long meiotic prophase, damage of spindle components whether by intrinsic factors or by the accumulation of environmental insults. For example, irradiation and heavy metal ions could affect oocytes through intracellular free radical production or oxidative effects. Radio-sensitivity of oocytes in the dictyate stage increases with advancing maternal age [54]. Not all chromosomes have equal sensitivity with chromosomes 21 and $\mathrm{X}$ being more susceptible to abnormal segregation [55].

\subsection{Relaxed selection hypothesis}

The propensity for affected fetuses to miscarry might decrease with advancing maternal age - relaxed selection [56]. If this were true the mean maternal age would be lower in trisomy 21 miscarriages than births. Since normal miscarriage increases with age [57] the hypothesis can best be tested by comparing the maternal age difference between miscarriages and births for DS with that for normal pregnancies. In the two large New York and Hawaii studies which karyotyped large numbers of miscarriages the difference for normal pregnancies was 1.0 years [58] compared with 1.2-1.8 years in New York and 0.3 years in Hawaii [59], an inconsistent result.

Moreover, the results of assisted reproduction using donor oocytes from young women in older recipients [51] indicate that it is the quality of the donated oocyte rather than the recipients' ability to select against abnormal embryos that determines a successful outcome. Furthermore, if there is relaxed selection against DS the mean maternal age would be increased in Robertsonian translocation cases as well as non-disjunction cases, and it is not [1].

Even if relaxed selection did contribute to the maternal age effect it could not account for all of it since the incidence of trisomy 21 in miscarriages also increases with maternal age [58].

\subsection{Premature reproductive ageing hypothesis}

Physiological ageing of the female reproductive system may be more important than chronological age per se; for example, depletion of the oocyte pool by accelerated atresia would lead to increased risk of trisomy [60]. In this context it is suggestive that the exponential decline in the number of available follicles after age 30 [61] mirrors the exponential rise in DS risk.

Experiments with inbred CBA mice, which have a small number of oocytes that are completely depleted by the time ovulation ceases, support this concept. Unilateral oophorectomy caused increased ovulation in the contralateral ovary, an early menopause and increased aneuploidy risk at all ages [62]. 
Two human studies have reported reduced menopausal age in association with trisomy: in the first menopause was on average 10.2 years after a DS birth compared with 12.8 years for controls [63]; in the second the mean age of menopause among women with trisomic miscarriages was 1.0 years earlier than women with normal pregnancies [64]. Unilateral oophorectomy is likely to bring forward the age of menopause, and surgical removal or congenital absence of one ovary is associated with a 9-fold increase in DS risk [65]. Women with Turner's syndrome have extremely premature menopause and there is a very large DS risk in their pregnancies: $1.8 \%$ (4/221) from reports in the literature [66-67].

The level of serum follicle stimulating hormone is an indicator of impending ovarian failure. Elevated levels have been reported in women with a previous DS pregnancy [68], and in women having early abortions for social reasons where karyotyping revealed fetal aneuploidy [69].

\subsection{Compromised microcirculation hypothesis}

This hypothesis proposes that non-disjunction arises from a cascading events [70]. The suggested sequence is hormonal imbalance, sub-optimal micro-vasculature around the ovarian follicle, reduced blood flow, increased carbon dioxide and lactic acid inside the follicle, decreased $\mathrm{pH}$ in the oocyte, reduced mitotic spindle size, spindle displacement and non-disjunction.

Whilst animal experiments do support the possibility that abnormal $\mathrm{pH}$ would lead to non-disjunction [71], two events in the sequence are controversial. Firstly, the proponents use the J-shape of the maternal age risk curve as evidence for the effect of hormonal imbalance around the time of menarche and approaching the menopause. However, none of the meta-analyses cited above demonstrate any relatively high DS risk in very young women. Secondly, the purported connection between compromised micro-circulation and reduced $\mathrm{pH}$, is the fact that the ovarian follicle has no internal circulation. But both oocytes and spermatocytes are isolated from direct contact with blood and it is known that the ovary is the most highly vascularized organ [72].

\subsection{Delayed fertilisation and sperm ageing hypotheses}

The secondary oocyte remains in MII metaphase in the Fallopian tube until it is fertilised. It has been proposed that ageing or over-ripeness of these cells could lead to a higher incidence of spindle defects and so increase the chance of non-disjunction. This hypothesis might explain the maternal age effect, since there is presumed to be a decreased frequency of coitus in older women [73]. Such behaviour would reduce the chance of fertilisation before the ovum became over-ripe.

There is epidemiological evidence which indicates that infrequent coitus may be a DS risk factor (see [29]). Some animal experiments show that chromosomal errors increase with delayed fertilisation, although it is difficult to distinguish this from the maternal age effect [74], and some animal experiments do not support the hypothesis; for a review see [75].

It has also been proposed that sperm ageing, for example as a result of infrequent coitus, could be involved. One possible mechanism is that chromosomally abnormal sperm are immature and have a competitive disadvantage over normal sperm, but a delay in utilisation would allow them to mature and there is some animal evidence for this [75].

\subsection{Mitochondrial (mt) DNA mutation hypothesis}

This proposal is that mtDNA mutations lead to a decline in ATP level and increased production of freeradicals, which could affect division spindle and chromosome segregation, accelerate telomere shortening, alter recombination and cause non-disjunction of chromosomes [76].

There are many features of mtDNA which are remarkably consistent with the epidemiology and molecular genetics of the disorder. The mtDNA is almost entirely of maternal origin, mtDNA mutations in oocytes increase with age [77] and the mutations can be inherited. There are also mtDNA mutations involved in Alzheimer's disease, diabetes and hypothyroidism, disorders which are relatively frequent in affected families.

In a mouse model, it has been shown that mtDNA mutations can modulate the expression of an inheritable MI error in oocytes [78]. In humans, the excess of maternal over paternal remarriages in families with aneuploidy recurrence to different partners, is consistent with a cytoplasmic risk factor [3]. There is increased freeradical activity in mothers which could be either a cause or result of mtDNA mutations [79]. The complete mtDNA was sequenced in a peripheral blood sample from the mother of a DS child who was the originator of the additional chromosome 21 [76]. There were four point mutations not previously described, each of which is likely to disrupt mitochondrial function. Similarly, three DS individuals were sequenced and a high incidence of potentially disruptive base changes were found [80].

\subsection{Way forward}

Now that the vast majority of DS birth can be prevented through antenatal screening a refocusing of research is called for with more effort placed on aetiology. Furthermore, the research effort needs to be more multidisciplinary than in the past. Although maternal age and family history are the main epidemiological variables there are many smaller but well established factors, such as a very reduced DS risk in twins, which may provide aetiological clues [4]. Those working at the molecular level, with animal models or in clinical chemistry need to be aware of these effects. Similarly, observations in the laboratory should be made known to epidemiologists so that comparable human evidence can be sought. With a concerted sustained effort large scale primary prevention may be realised in the near future.

\section{Conclusions}

From the beginning of their reproductive life women have the option to reduce the DS risk by completing their family by age 30 . On a population level this strategy could more than halve the birth prevalence of this disorder.

Women with a high a priori DS risk because of an inherited translocation or a previous pregnancy with a non-inherited form of DS should have access to PGD. The effectiveness of this technique is limited by the availability of normal embryos in such families but reasonably high pregnancy rates are achievable with an extremely low risk of a DS birth. However, only about $1 \%$ of DS pregnancies are in women with a family history of the disorder so the impact of this activity on birth prevalence is minimal. In some localities women of advanced reproductive age also 
have access to PGD which could potentially have a much greater impact on prevalence.

Biochemical, molecular and epidemiological evidence suggests a link between DS and a defect in folate and methyl metabolism. This is not sufficient to justify an active preventative strategy of folic acid supplementation without performing a large clinical trial. However, current supplementation policies designed to prevent NTDs may incidentally prevent DS, provided a sufficiently high dose of folic acid and possibly cobalamin is used.

Further progress in the primary prevention of DS is hampered by limited knowledge of the cause of this disorder. There is an urgent need to refocus research in that direction.

\section{Conflict of interest}

None declared.

\section{References}

1. Mutton D, Alberman E, Hook EB. Cytogenetic and epidemiological findings in Down syndrome, England and Wales 1989 to 1993. J Med Genet. 1996;33:387-394.

2. Cuckle HS, Wald NJ, Thompson SC. Estimating a women's risk of having a pregnancy associated with Down's syndrome using her age and serum alpha-fetoprotein level. $\mathrm{Br} \mathrm{J}$ Obstet Gynaecol. 1987;94:387-402.

3. Arbuzova S, Cuckle H, Mueller R, Sehmi I. Familial Down syndrome: evidence supporting cytoplasmic inheritance. Clin Genet. 2001;60:456-462.

4. Cuckle H, Arbuzova S. Epidemiology of aneuploidy. In: Evans MI, ed. Prenatal diagnosis: genetics, reproductive risks, testing, and management. York, PA, USA: Techbooks. 2005.

5. Hassold T, Sherman S. Down syndrome: genetic recombination and the origin of the extra chromosome 21. Clin Genet. 2000;57:95-100.

6. Avramopoulos D, Mikkelsen M, Vassilopoulos D, Grigoriadou M, Petersen MB. Apolipoprotein $\mathrm{E}$ allele distribution in parents of Down's syndrome children. Lancet 1996; 347:862-5.

7. Petersen MB, Karadima G, Samaritaki M, Avramopoulos D, Vassilopoulos D, Mikkelsen M. Association between presenilin-1 polymorphism and maternal meiosis II errors in Down syndrome. Am J Med Genet 2000;93(5):366-72.

8. James SJ, Pogribna M, Pogribny IP, Melnyk S, Hine RJ, Gibson JB, Yi P, Tafoya DL, Swenson DH, Wilson VL, Gaylor DW. Abnormal folate metabolism and mutation in the methylenetetrahydrofolate reductase gene may be maternal risk factors for Down syndrome. Am J Clin Nutr 1999; 70(4):495-501.

9. Hobbs CA, Sherman SL, Yi P, Hopkins SE, Torfs CP, Hine RJ, Pogribna M, Rozen R, James SJ. Polymorphisms in genes involved in folate metabolism as maternal risk factors for Down syndrome. Am J Hum Genet. 2000;67(3):623-30.

10. Petersen MB, Grigoriadou M, Mikkelsen M. A common mutation in the methylenetetrahydrofolate reductase gene is not a risk factor for Down syndrome in a population-based study. Am J Hum Genet 2001;69:323.

11. Chadefaux-Vekemans B, Coude M, Muller F, Oury JF, Chabli A, Jais J, Kamoun P. Methylenetetrahydrofolate reductase polymorphism in the etiology of Down syndrome. Pediatr Res. 2002;51(6):766-7.

12. O'Leary VB, Parle-McDermott A, Molloy AM, Kirke PN, Johnson Z, Conley M, Scott JM, Mills JL. MTRR and MTHFR polymorphism: link to Down syndrome? Am J Med Genet. 2002;107(2):151-5.

13. Stuppia L, Gatta V, Gaspari AR, Antonucci I, Morizio E, Calabrese G, Palka G. C677T mutation in the 5,10-MTHFR gene and risk of Down syndrome in Italy. Eur J Hum Genet. 2002;10(6):388-90.

14. Barkai G, Arbuzova S, Berkenstadt M, Heifetz S, Cuckle H. Frequency of Down's syndrome and neural-tube defects in the same family. Lancet 2003;361(9366):1331-5.

15. Cuckle H, Arbuzova S. Multianalyte Maternal Serum Screening for Chromosomal Defects. In: Milunsky A, ed. Genetic Disorders and the Fetus: Diagnosis, Prevention and Treatment - 5th edition. USA :Johns Hopkins University Press. 2004: 795-835
16. Green JM, Hewison J, Bekker HL, Bryant LD, Cuckle HS. Psychosocial aspects of genetic screening of pregnant women and newborns: a systematic review. Health Technol Assessment 2004; 8(33): 1-138.

17. Hecht CA, Hook EB. The imprecision in rates of Down syndrome by 1-year maternal age intervals: a critical analysis of rates used in biochemical screening. Prenat Diag. 1994; 14:729-738.

18. Hecht CA, Hook EB. Rates of Down syndrome at livebirth by oneyear maternal age intervals in studies with apparent close to complete ascertainment in populations of European origin: a proposed rate schedule for use in biochemical screening. Am J Med Genet. 1996;62:376-385.

19. Bray I, Wright DE, Davies CJ, Hook EB. Joint estimation of Down syndrome risk and ascertainment rates: a meta-analysis of nine published data sets. Prenat Diagn. 1998;18:9-20.

20. Morris JK, Mutton D, Alberman E. Revised estimates of the maternal age specific live birth prevalence of Down's syndrome. J Med Screen. 2002;9:2-6.

21. Cuckle H. Potential biases in Down syndrome birth prevalence estimation. J Med Screen. 2002;9(4):192.

22. Cuckle H. Down syndrome fetal loss rate in early pregnancy. Prenat Diag. 1999;19:1177-1179.

23. Office of National Statistics. Birth Statistics Series FM1 25. London: Office of National Statistics. 2004.

24. Cuckle H, Aitken D, Goodburn S, Senior B, Spencer K, Standing S. Age-standardisation for monitoring performance in Down's syndrome screening programmes. Prenat Diagn. 2004;24(11):851-856.

25. Stene E, Stene J, Stengel-Rutkowski S. A reanalysis of the New York State prenatal diagnosis data on Down's syndrome and paternal age effects. Hum Genet. 1987;77(4):299-302.

26. Hatch M, Kline J, Levin B, Hutzler M, Warburton D. Paternal age and trisomy among spontaneous abortions. Hum Genet. 1990;85(3):355361.

27. Lansac J, Thepot F, Mayaux MJ, Czyglick F, Wack T, Selva J, Jalbert P. Pregnancy outcome after artificial insemination or IVF with frozen semen donor: a collaborative study of the French CECOS Federation on 21,597 pregnancies. Eur J Obstet Gynecol Reprod Biol. 1997;74(2):223-8.

28. Boué A, Gallano P. A collaborative study of the segregation of inherited chromosome arrangements in 1356 prenatal diagnoses. Prenat Diagn. 1984;4:45-67.

29. Hook EBH. Prevalence, risk, and recurrence. In: Brock DJH, Rodeck $\mathrm{CH}$, Ferguson-Smith MA, eds. Prenatal Diagnosis and Screening. Edinburgh: Churchill Livingstone, 1992: 351-392.

30. Pangalos CG, Talbot CC Jr, Lewis JG, Adelsberger PA, Petersen MB, Serre JL, Rethore MO, de Blois MC, Parent P, Schinzel AA et al. DNA polymorphism analysis in families with recurrence of free trisomy 21. Am J Hum Genet. 1992;51(5):1015-27.

31. James RS, Ellis K, Pettay D, Jacobs PA. Cytogenetic and molecular study of four couples with multiple trisomy 21 pregnancies. European J Hum Genetics 1998;6:207-212.

32. Lim CK, Jun JH, Min DM, Lee H-S, Kim JY, Koong MK, Kang IS. Efficiency and clinical outcome of preimplantation genetic diagnosis using FISH for couples of reciprocal and Robertsonian translocations: the Korean experience. Prenat Diagn. 2004; 24(7):556561.

33. Munne S, Sandalinas M, Gianaroli L, Cohen J, Warburton D. Increased rate of aneuploid embryo in young women with previous aneuploid conceptions. Prenat Diagn. 2004; 24(8):638-643.

34. Kuliev A, Cieslak J, Ilkevitch Y, Verlinsky Y. Chromosomal abnormalities in a series of 6,733 human oocytes in preimplantation diagnosis for age-related aneuploidies. Reprod Biomed Online. 2003;6(1):54-9.

35. Fenech M. Recommended dietary allowances (RDAs) for genomic stability. Mutat Res 2001;480:51-54.

36. Wang X, Thomas P, Xue J, Fenech M. Folate deficiency induces aneuploidy in human lymphocytes in vitro-evidence using cytokinesis-blocked cells and probes specific for chromosomes 17 and 21. Mutat Res. 2004;551(1-2):167-80.

37. Zittoun J, Tonetti C, Bories D, Pignon J, Tulliez M. Plasma homocysteine levels related to interactions between folate status and 
methylenetetrahydrofolate reductase: a study in 52 healthy subjects. Metabolism 1998;47(11):1413-8.

38. Ashfield-Watt PA, Pullin CH, Whiting JM, Clark ZE, Moat SJ, Newcombe RG, et al. Methylenetetrahydrofolate reductase $677 \mathrm{C} \rightarrow \mathrm{T}$ genotype modulates homocysteine responses to a folate-rich diet or a low-dose folic acid supplement: a randomized controlled trial. Am J Clin Nutr 2002;76(1):180-6.

39. Amorim MR, Castilla EE, Orioli IM. Is there a familial link between Down's syndrome and neural tube defects? Population and familial survey. BMJ. 2004;328(7431):84.

40. Wald NJ, Law MR, Morris JK, Wald DS. Quantifying the effect of folic acid. Lancet 2001;358:2069-2073.

41. Homocysteine Trialists' Collaboration. Lowering blood homocysteine with folic acid based supplements: meta-analysis of randomised trials. Br Med J 1998;316(7135):894-8.

42. Kirke PN, Molloy AM, Daly LE, Burke H, Weir DG, Scott JM. Maternal plasma folate and vitamin B12 are independent risk factors for neural tube defects. Q J Med 1993;86(11):703-8.

43. Wilson A, Platt R, Wu Q, Leclerc D, Christensen B, Yang H, et al. A common variant in methionine synthase reductase combined with low cobalamin (vitamin B12) increases risk for spina bifida. Mol Genet Metab 1999;67:317-23.

44. Zetterberg H, Regland B, Palmer M, Rymo L, Zafiropoulos A, Arvanitis DA, Spandidos DA, Blennow K. The transcobalamin codon 259 polymorphism influences the risk of human spontaneous abortion. Hum Reprod. 2002 Dec;17(12):3033-6.

45. George L, Mills JL, Johansson AL, Nordmark A, Olander B, Granath F, Cnattingius S. Plasma folate levels and risk of spontaneous abortion. JAMA. 2002 Oct 16;288(15):1867-73.

46. Henderson SA, Edwards RG. Chiasma frequency and maternal age in mammals. Nature 1968;218:22-28.

47. Tease C, Fisher G. Further examination of the production-line hypothesis in mouse foetal oocytes. II. T(14;15)6Ca heterozygotes. Chromosoma 1986;93(5):447-452.

48. Tease C, Fisher G. Further examination of the production-line hypothesis in mouse foetal oocytes. I. Inversion heterozygotes. Chromosoma 1989;97(4):315-320.

49. Meredith S, Doolin D. Timing of activation of primordial follicles in mature rats is only slightly affected by fetal stage at meiotic arrest. Biol Reprod. 1997;57(1):63-67.

50. Polani PE, Crolla JA. A test of the production line hypothesis of mammalian oogenesis. Hum Genet. 1991;88(1):64-70.

51. Eichenlaub-Ritter U. Genetics of oocyte ageing. Maturitas 1998;30:143-169.

52. Polani PE, Briggs JH, Ford CE, Clarke CM, Berg JM. A Mongol girl with 46 chromosomes. Lancet 1960;i:721-724.

53. Choo KH. Role of acrocentric cen-pter satellite DNA in Robertsonian translocation and chromosomal non-disjunction. Mol Biol Med. 1990;7:437-449.

54. Tease C, Fisher G. The influence of maternal age on radiationinduced chromosome aberrations in mouse oocytes. Mutat Res. 1991;262(1):57-62.

55. Uchida IA, Lee CPV, Byrnes EM. Chromosome aberrations induced in vitro by low doses of radiation: nondisjunction in lymphocytes of young adults. Am J Hum Genet. 1975;27:419-429.

56. Ayme S, Lippman-Hand A. Maternal-age effect in aneuploidy: does altered embrionic selection play role? Am J Hum Genet. 1982;34:558565.

57. Nybo Anderson M-A, Wohlfahrt J, Christens P, Olsen J, Melbye M. Maternal age and fetal loss: population based register linkage study. Brit Med J. 2000;320:1708-1712.

58. Hassold T, Warburton D, Kline J, Stein Z. The relationship of maternal age and trisomy among trisomic spontaneous abortions. Am J Hum Genet. 1984;36:1349-1356.

59. Hook EB. Down syndrome rates and relaxed selection at older maternal ages. Am J Hum Genet. 1983;35(6):1307-1313.

60. Kline J, Levin B. Trisomy and age at menopause: predicted associations given a link with rate of oocyte atresia. Paediatr Perinat Epidemiol. 1992;6(2):225-239.

61. Brook JD, Gosden RG, Chandley AC. Maternal ageing and aneuploid embryos - Evidence from the mouse that biological and not chronological age is the important influence. Hum Genet. 1984;66:41-45.

62. Faddy MJ, Gosden RG, Gougeon A, Richardson SJ, Nelson JF. Accelerated disappearance of ovarian follicles in mid-life: implications for forecasting menopause. Human Reproduction. 1992;7:1342-1346.

63. Freeman SB, Yang Q, Allran K, Taft LF, Sherman SL. Women with a reduced ovarian complement may have an increased risk for a child with Down syndrome. Am J Hum Genet 2000;66(5):1680-1683.

64. Kline J, Kinney A, Levin B, Warburton D. Trisomic pregnancy and earlier age at menopause. Am J Hum Genet. 2000;67(2):395-404.

65. Phillips OP, Cromwell S, Rivas M, Simpson JL, Elias S. Trisomy 21 and maternal age of menopause: Does reproductive age rather than chronological age influence risk of nondisjunction? Hum Genet. 1995;95:117-118.

66. Tarani L, Lampariello S, Raguso G, Colloridi F, Pucarelli I, Pasquino AM, Bruni LA. Pregnancy in patients with Turner's syndrome: six new cases and review of literature. Gynecol Endocrinol. 1998;12(2):83-7.

67. Birkebaek NH, Cruger D, Hansen J, Nielsen J, Bruun-Petersen G. Fertility and pregnancy outcome in Danish women with Turner syndrome. Clin Genet. 2002;61:35-9.

68. van Montfrans JM, Dorland M, Oosterhuis GJ, van Vugt JM, RekersMombarg LT, Lambalk CB. Increased concentrations of folliclestimulating hormone in mothers of children with Down's syndrome. Lancet 1999;353:1853-1854.

69. Nasseri A, Mukherjee T, Grifo JA, Noyes N, Krey L, Copperman AB. Elevated day 3 serum follicle stimulating hormone and/or estradiol may predict fetal aneuploidy. Fertil Steril. 1999;71(4):715-718.

70. Gaulden ME. Maternal age effect: The enigma of Down syndrome and other trisomic conditions. Mutation Research 1992;296:69-88.

71. Shimada TG, Watanabe G, Ingalls TN. Trisomies and triploidies in hamster embryos: induction by low-pressure hypoxia and $\mathrm{pH}$ imbalances. Arch Environ Health. 1980;35:101-105.

72. Ellinwood WE, Nett TM, Niswender GD. Ovarian vasculature: structure and function. In: Jones RE, ed. The Vertebrate Ovary, Comparative Biology and Evolution. New York: Plenum; 1978: 583614.

73. German J. Mongolism, delayed fertilization and human sexual behaviour. Nature 1968;217:516-518.

74. Ishikawa H, Endo A. Combined effects of maternal age and delayed fertilization on the frequency of chromosome anomalies in mice. Hum Reprod. 1995;10(4):883-886.

75. Martin-DeLeon PA, Williams MB. Sexual behaviour and Down syndrome: the biological mechanism. Am J Med Genet. 1987;27:693700 .

76. Arbuzova S. Why it is necessary to study the role of mitochondrial genome in trisomy 21 pathogenesis? Down Syndrome Research and Practice 1989;5(3): 26-29.

77. Keefe DL, Niven-Fairchild T, Powell S, Buradagunta S. Mitochondrial deoxyribonucleic acid deletions in oocytes and reproductive ageing in women. Fertility \& Sterility 1995;64(3):577583.

78. Beerman F, Hummler E, Franke U, Hansmann I. Maternal modulation of the inheritable meiosis I error Dipl I in mouse oocytes is associated with the type of mitochondrial DNA. Hum Genet. 1988;79(4):338-340.

79. Arbuzova SB. Free radicals in origin and clinical manifestation of Down's syndrome. Cytology \& Genetics 1996;30:25-34.

80. Arbuzova S, Hutchin T, Cuckle H. Mitochondrial DNA mutations in Down's syndrome. Downs Screening News 2000;7(2):31.

\section{Author biography}

Howard S Cuckle (DPhil) is Professor of Reproductive Epidemiology at the University of Leeds. His unit provides antenatal screening services for a range of congenital abnormalities and heads the International Down's Syndrome Screening Group. Apart from developing newer and more efficient screening tests he is actively engaged on research into the aetiology of congenital abnormalities. 